\title{
A Review Study on Privacy Policy Inference of Multiple User-Uploaded Images on Social Context Websites
}

\author{
Himani Singh \\ M.Tech Student \\ Dept. ofComputerScience\&Engg, \\ Ajay Kumar Garg \\ Engineering College, UPTU, \\ Ghaziabad, India
}

\author{
Mamta Bhusry \\ Professor \\ Dept. ofComputer Science\&Engg \\ Ajay Kumar Garg \\ Engineering College, UPTU, \\ Ghaziabad, India
}

\begin{abstract}
Sharing images might prompt presentation of individual data and security breach. This collected data can be misused by unsafe clients. To anticipate such sort of undesirable acknowledgement of individual images, adaptable security settings are required. Recently, such security settings are made accessible and keeping up these measures is a cloudy and error inclined procedure. In this manner, suggestion framework is required which supply client with an adaptable help for organizing security settings in much easier way.
\end{abstract}

This paper includes the survey on different studies on privacy preserving for sharing images over social networking sites.

\section{Keywords}

Image Sharing, Privacy Preserving, Survey, Social Networking Sites, Traffic Rate

\section{INTRODUCTION}

Images are presently one of the key empowering influences of clients' network. Sharing occurs both among earlier established groups of known individuals or social circles (e.g., Google+, Flickr or Picasa), also gradually with individuals outside the clients social circles, for purposes of social revelation to offer them some assistance with identifying new friends and find out about associates interests and social environment. As it may, semantically rich images might uncover substance sensitive data. Consider an image of a student's 2012 graduation provision, for instance. It could be shared inside of a Google+ circle or Flickr group, however might pointlessly uncover the student's relatives and different friends. Sharing images inside online substance sharing sites, hence, might rapidly prompt undesirable revelation and protection breach. Further, the constant way of online media makes it feasible for different clients to collect high quality data about the owner of the distributed substance and the subjects in the distributed substance. The totaled data can bring about unexpected introduction of one's social environments and lead to exploit of one's personal information.

Most substance sharing sites permit clients to enter their security inclinations. Startlingly, recent studies have demonstrated that clients encounter to set up and maintain such security settings. One of the principle reasons gave is that given the measure of shared data this procedure can be monotonous and error inclined. In this way, numerous have recognized the need of policy proposal frameworks which can help clients to effectively and legitimately design protection settings. Be that as it may, current proposal for computerizing protection settings have all the allocates of being insufficient to address the special security needs of images because of the measure of data certainly conveyed inside of images, and their pertinence concerning the online social environment wherein they are uncovered.

Today, for each and every bit of substance shared on sites such as Facebook - each wall post, image, announcement, and video - the up loader must choose which of his companions, group individuals, and other Facebook clients ought to have the capacity to get to the substance. Subsequently, the issue of security on sites such as Facebook has gotten critical consideration in both the examination group and the standard media. We will likely enhance the policy of security controls and defaults, however we are constrained by the way that there has been no top to bottom investigation of clients' protection settings on sites such as Facebook. While critical security violation and failed client desires are prone to exist, the degree to which such protection violation happen has yet to be quantified.

\section{RELATED WORK}

In [3] proposes a method Privacy-Aware Image Classification and Search [8] to naturally identify private images and to empower protection planned image. It joins literary Meta data images with range of visual elements to give security approaches. In this the chose image features (edges, confronts, shading histograms) which can segregate in the middle of regular and synthetic items/scenes (the EDCV feature) that can show the vicinity or nonattendance of specific articles (SIFT). It utilizes different order models prepared on a huge scale dataset with security assignments got through a social explanation diversion.

Taking in the Semantics of Words and Images [5] present a technique which arranges image databases utilizing both image features and relational content. By incorporating the two sorts of data amid model development, the framework learns joins between the image components and semantics which can be misused for better scanning, better search, and novel applications, for example, partner words with images, and unsupervised learning for object recognition.

In [6] added to a methodology Markovian Semantic Indexing (MSI) another policy for programmed explanation and comment based image recovery. The proposed framework permits the recovery method to profit by the hidden structure of the explanation information. The proposition is to give the best image in light of the client inquiry with the dynamic control. At the point when the client selected on the image the indexing is consequently performed and the query output will be shown. It gives proficient and viable search result.

In [7] discussed Markovian Semantic Indexing (MSI) for programmed explanation based image recovery. This technique is suitable for Annotation Based Image Retrieval (ABIR) when the per image explanation information is restricted. In the 
current work, Adaptive Privacy Policy Prediction (A3P) framework is utilized to offer clients some assistance with composing security settings for their images. The A3P framework comprises of two primary segments: A3P-center and A3P-social. At the point when a client transfers an image, the image will be first sent to the A3Pcore. The A3P-center characterizes the image and figures out if there is a need to call the A3P-social. As a rule, the A3P-center predicts approaches for the clients specifically taking into account their historical behavior.

A3P-core will summon A3P social when the client does not have enough information for the kind of the transferred image to direct approach forecast and the A3P-center distinguishes the recent real changes among the client's group about their security improves alongside client's increment of long range interpersonal communication exercises, for example, expansion of new friends, new poles on one's profile and so forth. In above cases, it is advantageous to answer to the client the most recent protection routine of social groups that have comparative background as the user [8].

\section{A. A3P-CORE}

There are two major components in A3P-core: (i) Image classification and (ii) Adaptive policy expectation. For every client, his/her images are initially ordered in view of substance and metadata. At that point, protection approaches of every class of images are investigated for the policy expectation. Embracing a two-stage methodology is more suitable for classification suggestion than applying the normal one-stage information mining ways to deal with mine both image components and strategies together. Review that when a client transfers another image, the client is waiting for a recommended policy.

\section{B. Image Classification}

To acquire groups of images that might be connected with comparable security inclinations, we propose a various leveled image grouping which characterizes images initially in light of their substance and after that refine every classification into subcategories in view of their metadata. Images that don't have metadata will be assembled just by substance. Such a progressive classification gives a higher need to image content and minimizes the impact of missing tags.

\section{Adaptive Policy Prediction}

The policy prediction algorithm gives an anticipated approach of a recently transferred image to the client for his/her reference. All the more significantly, the anticipated classification will mirror the conceivable changes of a client's security concerns. The forecast process comprises of three principle stages: (i) classification standardization; (ii) policy mining; and (iii) approach expectation. The policy standardization is a basic disintegration procedure to change over a client approach into a classification of particular rules in which the Data (D) part is a single-element set.

\section{PRIVACY IN ONLINE SOCIAL NETWORKS}

A few studies have analyzed clients' concerns identified with sharing on online informal organizations (OSNs).

Krasnova et al. utilized center groups to find that clients had an expansive scope of pressures, going from oversharing with friends, relatives, and associates to their online information being extracted by enterprises [9].

Besmer and Lipford analyzed clients' uncertainties about sharing images, comparatively finding that informal organization protection devices don't attractively address clients' needs [10].

Johnson et al. found that while the greater part of interpersonal organization clients is concerned about uncovering data to outsiders, most clients have found a way to alleviate these uncertainties (e.g., by utilizing suitable protection approaches); then again, numerous clients additionally had particular concerns about offering substance to companions and associates that they were not tending to as viably [11].

$\mathrm{Hu}$ et al. explain how policy clashes can emerge when various clients have a stake in the security policy (e.g., different Facebook clients that are labeled in an image) and recommend techniques for determining such clashes [12].

Liu et al. discovered predominant utilization of default security settings and a low match between protection settings and clients' needs [13]. Different experts found through a top to bottom convention think about that OSN clients regularly overshare and think twice about it [14], with particular outcomes extending from provisional disgrace to damaged sentimental connections and lost employments. The consequences of client study are predictable with these outcomes.

Tufecki reported finding no relationship among clients' OSN sharing propensities and their uncertainties about the protection of their age, sexual orientation, intrigues, and other comparable profile data [15]. Recent confirmation, in any case, recommends that the powerlessness of clients to have certainty that their dynamic substance (e.g., notices and posts) will be shared by inclinations is a main consideration in deciding the recurrence of utilization of informal societies.

Table II: Privacy in online social networks

\begin{tabular}{|l|l|l|}
\hline Author/Year & Name of Research & Research approach \\
$\begin{array}{l}\text { H. Hu, G.-J. } \\
\text { Jorgensen. } \\
\text { (2011) }\end{array}$ & $\begin{array}{l}\text { Detecting and } \\
\text { resolving privacy } \\
\text { conflicts for } \\
\text { collaborative data } \\
\text { sharing in online } \\
\text { social networks }\end{array}$ & $\begin{array}{l}\text { Utilized center } \\
\text { groups to find that } \\
\text { clients had an } \\
\text { expansive scope of } \\
\text { pressures }\end{array}$ \\
\hline $\begin{array}{l}\text { Y. Liu et. al. } \\
\text { (2011) }\end{array}$ & $\begin{array}{l}\text { Analyzing } \\
\text { Facebook privacy } \\
\text { settings: user } \\
\text { expectations vs. } \\
\text { reality }\end{array}$ & $\begin{array}{l}\text { ancertainties about } \\
\text { sharing images }\end{array}$ \\
\hline $\begin{array}{l}\text { Y. Wang et. al. } \\
\text { (2011) }\end{array}$ & $\begin{array}{l}\text { Privacy concerns } \\
\text { and identity in } \\
\text { online social } \\
\text { networks }\end{array}$ & $\begin{array}{l}\text { found that while the } \\
\text { greater part of } \\
\text { interpersonal } \\
\text { organization clients is } \\
\text { concerned about } \\
\text { uncovering data to } \\
\text { outsiders }\end{array}$ \\
\hline
\end{tabular}




\begin{tabular}{|l|l|l|}
\hline (2008) & $\begin{array}{l}\text { now? Audience } \\
\text { and disclosure } \\
\text { regulation in } \\
\text { online social } \\
\text { network sites }\end{array}$ & $\begin{array}{l}\text { clashes can emerge } \\
\text { when various clients } \\
\text { have a stake in the } \\
\text { security policy }\end{array}$ \\
\hline $\begin{array}{l}\text { J. Staddon, et. } \\
\text { al. (2012) }\end{array}$ & $\begin{array}{l}\text { Are privacy } \\
\text { concerns a turn- } \\
\text { off? Engagement } \\
\text { and privacy in } \\
\text { social networks }\end{array}$ & $\begin{array}{l}\text { Discovered } \\
\text { predominant } \\
\text { utilization of default } \\
\text { security settings and } \\
\text { a low match between } \\
\text { protection settings } \\
\text { and clients' needs }\end{array}$ \\
\hline $\begin{array}{l}\text { A. L. Young } \\
\text { and A. Quan- } \\
\text { Haase. (2009) }\end{array}$ & $\begin{array}{l}\text { Information } \\
\text { revelation and } \\
\text { Internet privacy } \\
\text { concerns on social } \\
\text { network sites: a } \\
\text { case study of } \\
\text { Facebook }\end{array}$ & $\begin{array}{l}\text { reported finding no } \\
\text { relationship among } \\
\text { clients' OSN sharing } \\
\text { propensities }\end{array}$ \\
\hline
\end{tabular}

\section{COPYING STRATEGIES AND MECHANISMS}

In response to these issues, clients utilize various adapting systems past the elements offered by OSNs. A few clients moved far from telecast content (e.g., announcements and posts) towards private messages [16]. Others maintain numerous online profiles or records, utilizing each to collaborate with an alternate group of people. At last, erasing companions and posts and expelling labels from posts are additionally progressively utilized. Likewise trying to alleviate these issues, OSNs have been upgraded with elements that make it less demanding for clients to set and comprehend protection classifications. These incorporate Facebook's, Google's "circles," "Special Lists," and interfaces that permit a client to comprehend in subtle element which of her distributed substance is obvious to which different clients (e.g., Facebook's "Crowd View").

Researchers have additionally progressed new apparatuses and methodologies, including better perceptions of companion groups and systems [17], and explored different avenues regarding distinctive classification creation methodologies, for example, tag-based policy, in which approaches are determined only as far as labels with which substance is named [18]. Although every one of these instruments offer, none that some assistance with having been conveyed have been accounted for to altogether moderate clients' uncertainties and issues with oversharing (e.g., [11]).

\section{AUTOMATED SUPPORT FOR POLICY SPECIFICATION}

There is a long history of utilizing machine computing out how to distinguish approaches or determine policy. An early focus of such examination was firewall strategies, for which instruments were created to separate approaches for consistency or the locality of indicated properties (e.g., $[3,1])$. Comparative methodologies were utilized to recommend firewalling executive's strategies that match pre-determined objectives [16]. Different works utilized guideline mining and Bayesian surmising to dissect switch approaches and naturally identify classification problems.

Das et al. dissected fileserver access-control policy to identify irregularities in the consents given to generally comparative clients [19]. Bauer et al. studied logs of gets to physical space and surmised which potential gets to that are not allowed by classification are reliable with surveyed gets to [20].

Earlier to this present paper's center, machine learning has been utilized to arrange images transferred to substance sharing destinations and to propose sharing approaches [21]. In that work, images are initially planned by substance, and after that the subsequent classes are further separated in view of engaging labels that clients join to the images. Our work seeks after a comparative objective for content substance, for example, posts and notices; however the particular algorithms and components utilized for grouping as a part of the two methodologies contrast.

Fang et al., addresses the issue of permitting companions access to data in a client's OSN profile [22]. These works expect that there is a hidden security inclination that should be learned. The issue we address is distinctive, as we expect to predict the entrance control policy that ought to be connected to status messages, which includes mapping data contained in a status message to the privacy setting.

\section{CONCLUSION}

This paper represents different protection classification procedures for client transferred information and images in different substance sharing sites. The security approach can be connected in view of the client social behavior and the client transferred image content. Our review results demonstrate that the classifications chosen by members are frequently not able of the proposed policy, both affecting the execution of machine-learning algorithms and making it testing to decipher results. We utilize members' inputs to remedy their protection approach, which depends on the basic supposition that clients can legitimately allocate security classifications amid the review.

\section{REFERENCES}

[1] M. Ames and M. Naaman, (2007). "Why we tag: Motivations for annotation in mobile and online media," in Proc. Conf. Human Factors Comput. Syst., pp. 971980.

[2] A. Besmer and H. Lipford, (2009). "Tagged photos: Concerns, perceptions, and protections," in Proc. 27th Int. Conf. Extended Abstracts Human Factors Comput. Syst., pp. 4585-4590.

[3] D. G. Altman and J. M. Bland, (1995). "Multiple significance tests: The bonferroni method," Brit. Med. J., vol. 310 , no. 6973 .

[4] J. Bonneau, J. Anderson, and L. Church, (2009). "Privacy suites: Shared privacy for social networks," in Proc. Symp. Usable Privacy Security.

[5] J. Bonneau, J. Anderson, and G. Danezis, (2009). "Prying data out of a social network," in Proc. Int. Conf. Adv. Soc. Netw. Anal. Mining, pp.249-254.

[6] A. Mazzia, K. LeFevre, and E. Adar. (2012). "The PViz comprehension tool for social network privacy settings," in Proc. SOUPS. 
[7] P. F. Klemperer, Y. Liang, M. L. Mazurek, M. Sleeper, B. Ur, L. Bauer, L. F. Cranor, N. Gupta, and M. K. Reiter. (2012). "Tag, you can see it! Using tags for access control in photo sharing," in Proc. CHI.

[8] T. Jaeger, A. Edwards, and X. Zhang. (2003). "Policy management using access control spaces," ACM Transactions on Information and System Security, 6(3):327-364

[9] H. Krasnova, O. Günther, S. Spiekermann, and K Koroleva. (2009). "Privacy concerns and identity in online social networks," Identity in the Information Society, 2:39-63.

[10] A. Besmer and H. Richter Lipford. (2010). "Moving beyond un-tagging: Photo privacy in a tagged world," In Proc. CHI.

[11] M. Johnson, S. Egelman, and S. M. Bellovin. (2012) "Facebook and privacy: It's complicated," In Proc. SOUPS.

[12] H. Hu, G.-J. Ahn, and J. Jorgensen. (2011). "Detecting and resolving privacy conflicts for collaborative data sharing in online social networks," in Proc. ACSAC.

[13] Y. Liu, K. P. Gummadi, B. Krishnamurthy, and A Mislove. (2011). "Analyzing Facebook privacy settings: user expectations vs. reality," in Proc. IMC.

[14] Y. Wang, G. Norcie, S. Komanduri, A. Acquisti, P. G. Leon, and L. F. Cranor. (2011). "I regretted the minute I pressed share: a qualitative study of regrets on Facebook," in Proc. SOUPS.
[15] Z. Tufekci. (2008). "Can you see me now? Audience and disclosure regulation in online social network sites," Bulletin of Science, Technology \& Society, 28(1):20-36.

[16] J. Staddon, D. Huffaker, L. Brown, and A. Sedley. (2012). "Are privacy concerns a turn-off? Engagement and privacy in social networks," in Proc. SOUPS.

[17] E. Hayashi, O. Riva, K. Strauss, A. J. B. Brush, and S. Schechter. (2012). "Goldilocks and the two mobile devices: going beyond all-or-nothing access to a device's applications," In Proc. SOUPS.

[18] A. L. Young and A. Quan-Haase. (2009). "Information revelation and Internet privacy concerns on social network sites: a case study of Facebook," In Proc. 4th International Conference on Communities and Technologies, 2009.

[19] T. Das, R. Bhagwan, and P. Naldurg. (2010). "Baaz: A system for detecting access control misconfigurations," In Proc. USENIX Security Symposium.

[20] L. Bauer, S. Garriss, and M. K. Reiter. (2011). "Detecting and resolving policy misconfigurations in access-control systems," ACM TISSEC, 14(1).

[21] A. C. Squicciarini, S. Sundareswaran, D. Lin, and J. Wede. (2011). "A3P: adaptive policy prediction for shared images over popular content sharing sites," in Proc. Hypertext.

[22] L. Fang and K. LeFevre. (2010). "Privacy wizards for social networking sites," in Proc. WWW. 